\title{
Malignant melanoma brain metastases: Treatment results and prognostic factors - a single-center retrospective study
}

\author{
CHRISTIAN OSTHEIMER ${ }^{1 *}$, CAROLINE BORMANN $^{1 *}$, ECKHARD FIEDLER $^{2}$, \\ WOLFGANG MARSCH ${ }^{2}$ and DIRK VORDERMARK ${ }^{1}$ \\ Departments of ${ }^{1}$ Radiation Oncology and ${ }^{2}$ Dermatology, Martin Luther University \\ Halle-Wittenberg, D-06120 Halle (Saale), Germany
}

Received February 18, 2015; Accepted March 27, 2015

DOI: 10.3892/ijo.2015.2970

\begin{abstract}
The brain is one of the most frequent locations of metastasis in malignant melanoma. We aimed to identify prognostic factors for overall survival (OS) and local tumor control (LC) in patients with malignant melanoma metastasized to the brain treated by multimodal therapy. All patients diagnosed with malignant melanoma brain metastases between 1992 and 2011 at a single center were registered $(n=100,65 \%$ male, $35 \%$ female). OS and LC of individual brain metastases were retrospectively analyzed. Subgroup analyses was performed in patients with multiple brain metastasis $(n=35)$ and LC per lesion $(n=72)$ was evaluated in 37 patients. Median age was 57 (27-81) years. Fifty-three percent of patients had 1-2 brain metastases, $47 \%$ had $>2$ and $71 \%$ presented with additional extracranial metastases. Primary treatment included systemic therapy alone (temozolomide/fotemustine, 14\%), local therapy (surgery and/or stereotactic radiotherapy, 25\%), whole-brain radiotherapy (WBRT, 10\%), combined WBRT and systemic therapy (18\%), local therapy plus WBRT (5\%) and combination of local and systemic therapy (8\%). Three percent received a tri-modal therapy (WBRT, local and systemic therapy) and $17 \%$ refused treatment. Median follow-up in surviving patients was 32 (4-222) months, median OS in all patients 3.9 months (1-year survival 21.4\%). Local therapy $(\mathrm{p}<0.001)$, systemic therapy $(\mathrm{p}=0.002)$, number of brain metastases and primary therapy including a local therapy $(\mathrm{p}<0.001)$ were significantly associated with OS. In the subgroup with multiple brain metastases $(n=35)$, a trend $(p=0.058)$ for improved OS after initial treatment with WBRT plus systemic therapy was noted (median OS 3.8 months) and use of these two modalities over the course of the disease was significantly associated with
\end{abstract}

Correspondence to: Dr Christian Ostheimer, Department of Radiation Oncology, Martin Luther University Halle-Wittenberg, Ernst-Grube-Strasse 40, D-06120 Halle (Saale), Germany

E-mail: christian.ostheimer@uk-halle.de

*Contributed equally

Key words: malignant melanoma, metastatic melanoma, prognostic factors, brain metastasis, advanced melanoma, predictive factors, survival, radiotherapy
OS $(p=0.007)$. The best LC per single lesion $(n=37)$ could be achieved by combination of local with systemic therapy $(p=0.011)$. Number of brain metastases, extracranial metastases and use of local therapy are independent prognostic factors in melanoma metastatic to the brain. LC and OS can be improved by combining local with systemic treatment. In patients with multiple brain metastases, WBRT plus systemic therapy provides superior OS.

\section{Introduction}

Malignant melanoma is one of the most common causes of brain metastases (1-3) which is reported in $10-40 \%$ of melanoma patients (4-6). Lifetime incidence of central nervous system (CNS) involvement in patients with malignant melanoma is reported with $\sim 10 \%$ in the literature $(7,8)$ and drastically limits prognosis: survival of untreated patients is only weeks, treated patients will live $<1$ year despite a small number of long-term survivors with a 10 -year survival $<10 \%$ (9-12). Patients with multiple brain metastases have a reported OS of 3-4 months $(10,13)$.

Brain metastasis is the main cause of mortality and morbidity among patients with metastatic melanoma $(13,14)$ where $73 \%$ of patients who died from malignant melanoma showed subclinical brain involvement as evidenced by autopsy (14-16).

Few studies elucidated potential risk factors for the development of brain metastases in malignant melanoma including gender, Breslow thickness, ulceration, melanoma location, histological type, certain genetic alterations (i.e., BRAF mutation) and positive sentinel node $(7,17-19)$.

There are data from randomized trials comparing wholebrain radiotherapy (WBRT) and chemotherapy in patients with melanoma metastatic to the brain where treatment decision depends on clinical factors such as size, location, number of metastases, disease extent but also performance status and the age of the patients (20-22). Treatment approaches to metastatic malignant melanoma include systemic therapy $(23,24)$ as well as local treatment such as stereotactic radiotherapy (25) and surgery $(26,27)$ for patients with solitary brain metastasis and absent or stable extracranial disease (28). Patients with inoperable or multiple brain metastases may be candidates for WBRT (29) which is also part of the multimodal treatment 
concept of metastatic malignant melanoma $(21,30,31)$ with an expected median survival of 2.5-4 months after hypofractionated radiotherapy (32) as opposed to steroid therapy alone $(33,34)$. However, both the treatment sequence and the decision for a validated standard approach of combined therapy in metastasized melanoma can be challenging $(35,36)$.

The objective of this single-center retrospective clinical study was to identify potential prognostic factors for OS and LC and to investigate the influence of different treatment modalities in patients with malignant melanoma metastatic to the brain.

\section{Materials and methods}

We retrospectively analyzed 100 consecutive patients with histologically confirmed malignant melanoma who presented with metastases at Martin Luther University Halle-Wittenberg, Department of Radiation Oncology or Department of Dermatology between April 1992 and October 2011. A positive vote was given and the study was approved by the ethics committee of the Medical Faculty of the Martin Luther University Halle-Wittenberg. Sociodemographic and clinical patient data were collected from the patients' charts, the intracranial course of disease was evaluated with CT or MRI and survival status was obtained for each patient via local citizen registration offices.

Endpoints in this study were overall survival (OS, from initial diagnosis of brain metastasis until death or last seen), local tumor control per single lesion (LC, i.e., no size increase of present metastases, absence of recurrence of treated metastases and of hemorrhage) and intracranial tumor control (absence of recurrence of treated metastases, absence of new metastases, absence from size increase and hemorrhage of present brain metastases). Tumor control was based on the time until local progression occurred or absence of local progression was last documented at follow-up.

OS and intracranial tumor control per patient were evaluated for the entire patient cohort $(n=100)$ and LC per single lesion ( $n=72$ lesions) was assessed in $n=37$ patients with any available follow-up imaging.

Statistical analyses were performed using the Statistica software (version 10, StatSoft, Tulsa, OK, USA). The KaplanMeier method was used in the univariate evaluation of potential prognostic factors and the log-rank test compared survival between subgroups. Significant factors from the univariate analysis were included in the multivariate analysis using a multiple Cox regression. Statistical significance was accepted with two-sided p-values $<0.05$.

\section{Results}

Patient, tumor and treatment characteristics. Sixty-five percent of patients were male, $35 \%$ female. Median age at the time of initial diagnosis of malignant melanoma was 57 (27-81) years and median age at the time of diagnosis of brain metastasis was 62 (28-81) years. The median time from first diagnosis of malignant melanoma to occurrence of brain metastasis was 2.5 years (50 days - 17.3 years). Clinical melanoma characteristics are presented in Table I, and Table II shows characteristics of brain metastasis.
Table I. Clinical melanoma characteristics $(n=100)$.

\begin{tabular}{|c|c|}
\hline Characteristic & Patients n $(\%)$ \\
\hline \multicolumn{2}{|l|}{ Histology } \\
\hline $\mathrm{SSM}^{\mathrm{a}}$ & $29(29)$ \\
\hline $\mathrm{NM}^{\mathrm{b}}$ & $42(42)$ \\
\hline $\mathrm{ALM}^{\mathrm{c}}$ & $5(5)$ \\
\hline $\mathrm{UCM}^{\mathrm{d}}$ & $11(11)$ \\
\hline Unkown primary & $13(13)$ \\
\hline $\mathrm{LMM}^{\mathrm{e}}$ & $0 \quad(0)$ \\
\hline \multicolumn{2}{|l|}{ Breslow $^{\mathrm{f}}$} \\
\hline$<2 \mathrm{~mm}$ & $30(30)$ \\
\hline$>2 \mathrm{~mm}$ & $51(51)$ \\
\hline Unknown & $19(19)$ \\
\hline \multicolumn{2}{|l|}{ Ulceration } \\
\hline Yes & $39(39)$ \\
\hline No & $36(36)$ \\
\hline Unknown & $25(25)$ \\
\hline \multicolumn{2}{|l|}{ Stage $^{g}$} \\
\hline $1 \mathrm{~A}$ & $6(6)$ \\
\hline $1 \mathrm{~B}$ & $14(14)$ \\
\hline $2 \mathrm{~A}$ & 19 (19) \\
\hline $2 \mathrm{~B}$ & $0 \quad(0)$ \\
\hline $2 \mathrm{C}$ & $10(10)$ \\
\hline $3 \mathrm{~A}$ & $2(2)$ \\
\hline $3 \mathrm{~B}$ & $18(18)$ \\
\hline $3 \mathrm{C}$ & $0 \quad(0)$ \\
\hline 4 & $23(23)$ \\
\hline Unknown & $8 \quad(8)$ \\
\hline \multicolumn{2}{|l|}{ Clark-Level } \\
\hline I & $0 \quad(0)$ \\
\hline II & $11(11)$ \\
\hline III & $29(29)$ \\
\hline IV & $27(27)$ \\
\hline $\mathrm{V}$ & $12(12)$ \\
\hline Unknown & $21(21)$ \\
\hline \multicolumn{2}{|c|}{ Initial lymph node metastases $\mathrm{s}^{\mathrm{g}}$} \\
\hline Yes & $22(22)$ \\
\hline No & $56(56)$ \\
\hline $\mathrm{N} / \mathrm{A}$ & $22(22)$ \\
\hline \multicolumn{2}{|c|}{ Lymph node metastases ${ }^{\mathrm{i}}$} \\
\hline Yes & $61(61)$ \\
\hline No & $39(39)$ \\
\hline \multicolumn{2}{|c|}{ Extracranial metastases $^{\mathrm{j}}$} \\
\hline Yes & $71(71)$ \\
\hline No & $29(29)$ \\
\hline \multicolumn{2}{|c|}{ Organ systems affected by metastases ${ }^{\mathrm{j}}$} \\
\hline 0 & $29(29)$ \\
\hline 1 & $25(25)$ \\
\hline 2 & $22(22)$ \\
\hline 3 & $18(18)$ \\
\hline 4 & $6(6)$ \\
\hline
\end{tabular}

${ }^{\text {aS }}$ uperficial spreading melanoma. ${ }^{\mathrm{b}}$ Nodular melanoma. ${ }^{\mathrm{c}}$ Acral lentiginous melanoma. ${ }^{\mathrm{d}}$ Unclassified melanoma. ${ }^{\mathrm{e}}$ Lentigo malignant melanoma. ${ }^{\mathrm{f}}$ Vertical tumor depth, median, $2 \mathrm{~mm} .{ }^{\mathrm{g}}$ According to AJCC

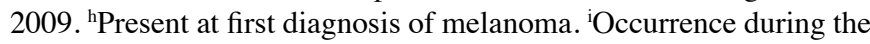
disease course. ${ }^{j}$ Independent from diagnosis of brain metastases. 
Table II. Characteristics of brain metastases $(n=100)$.

\begin{tabular}{|c|c|}
\hline Characteristic & Patients n $(\%)$ \\
\hline \multicolumn{2}{|l|}{ Initial imaging } \\
\hline CT & $77(77)$ \\
\hline MRI & $21(21)$ \\
\hline Unknown & $2(2)$ \\
\hline \multicolumn{2}{|c|}{ Number at initial diagnosis } \\
\hline $1-2$ & $53(53)$ \\
\hline$>2$ & $47(47)$ \\
\hline \multicolumn{2}{|l|}{ Location } \\
\hline Supratentorial & $95(95)$ \\
\hline Infratentorial & 4 (4) \\
\hline Both & $1 \quad(1)$ \\
\hline \multicolumn{2}{|l|}{ Symptoms } \\
\hline Yes & $71(71)$ \\
\hline No & $25(25)$ \\
\hline Unknown & 4 (4) \\
\hline \multicolumn{2}{|l|}{ Hemorrhage } \\
\hline Yes & $22(22)$ \\
\hline No & $71(71)$ \\
\hline Unknown & 7 (7) \\
\hline \multicolumn{2}{|l|}{ Size } \\
\hline$<20 \mathrm{~mm}$ & $48(48)$ \\
\hline$>20 \mathrm{~mm}$ & $51(51)$ \\
\hline \multicolumn{2}{|l|}{ Midline shift } \\
\hline Yes & $18(18)$ \\
\hline No & $72(72)$ \\
\hline Unknown & $10(10)$ \\
\hline \multicolumn{2}{|l|}{ Brain edema } \\
\hline Yes & $67(67)$ \\
\hline No & $25(25$ \\
\hline Unknown & $8(8)$ \\
\hline
\end{tabular}

Seventy-one percent of patients were diagnosed with additional extracranial metastases and in $46 \%$, more than one organ system was affected, including lung in 54 patients $(54 \%)$, liver in 35 patients $(35 \%)$, bone in 16 patients $(16 \%)$ and skin in 42 patients $(42 \%)$. Sixteen percent of patients had distant lymph node metastases.

In $71 \%$ of patients, CNS symptoms from cerebral metastasis were reported and included seizures, behavioral changes, headache and speech disorder; in $25 \%$ of patients, cerebral metastases were asymptomatic and an incidental finding during melanoma staging investigations.

Treatment characteristics (Table III). Prior to diagnosis of brain metastasis, 50 patients $(50 \%)$ were treated systemically with dacarbazine $(6 \%)$, interferon $\alpha(23 \%)$ or a combination of both $(21 \%)$. In the entire patient collective, 45 patients $(45 \%)$ received WBRT which was delivered in an opposing-field photon technique with a median single dose of 2.5 (2-5) Gy and a median total dose of 33 (6-54) Gy. Cranial stereotactic radiotherapy was carried out as a CT-based hypofractionated
Table III. Treatment characteristics $(n=100)$.

\begin{tabular}{|c|c|c|}
\hline \multirow{2}{*}{$\begin{array}{l}\text { Characteristic } \\
\text { 1. Primary therapy } 2 \text {. Whole therapy }\end{array}$} & \multicolumn{2}{|c|}{ Patients n (\%) } \\
\hline & 1. & 2. \\
\hline WBRT $^{\mathrm{a}}$ only & $10(10)$ & $10(10)$ \\
\hline Systemic therapy only & $14(14)$ & $9 \quad(9)$ \\
\hline Local therapy only & $26(26)$ & $16(16)$ \\
\hline WBRT $^{\mathrm{a}}+$ systemic therapy & $18(18)$ & $19(19)$ \\
\hline WBRT $^{\mathrm{a}}+$ local therapy & $5(5)$ & $3(3)$ \\
\hline Systemic + local therapy & $8(8)$ & $15(15)$ \\
\hline $\mathrm{WBRT}^{\mathrm{a}}+$ systemic + local therapy & $3(3)$ & $12(12)$ \\
\hline No treatment & $16(16)$ & $16(16)$ \\
\hline \multicolumn{3}{|l|}{ Systemic agents used } \\
\hline Temozolomide & \multicolumn{2}{|c|}{$41(41)$} \\
\hline Fotemustine & \multicolumn{2}{|c|}{$18(18)$} \\
\hline Both & \multicolumn{2}{|c|}{$3(3)$} \\
\hline Neither & \multicolumn{2}{|c|}{$44(44)$} \\
\hline
\end{tabular}

${ }^{\mathrm{a}}$ Whole brain radiotherapy.

radiotherapy or radiosurgery for 1-3 lesions in 52 patients $(52 \%)$, in one patient, it was administered for $\leq 4$ cerebral lesions. A custom-made individual immobilization mask was used for each patient, median single dose was 5.5 (2-25) Gy and median total dose 25 (12-50) Gy.

Systemic treatment was given with either temozolomide or fotemustine or both (1-12 courses per patient, median 1 course). Median absolute dose of temozolomide was 270 (min. 140 - $\max$. 420) $\mathrm{mg} / \mathrm{m}^{2}$ body surface (equivalent to $200 \mathrm{mg} / \mathrm{m}^{2}$ body surface per day) and patients received this medication orally for 5 consecutive days, followed by an interruption of 23 days before the start of the next course. Fotemustine was daily administered intravenously with a dose of $100 \mathrm{mg} / \mathrm{m}^{2}$ body surface (days 1, 8 and 15), followed by a break of 5 weeks before maintenance therapy was initiated with $100 \mathrm{mg} / \mathrm{m}^{2}$ body surface once weekly every 3 weeks.

Treatment for patients with multiple brain metastases was delivered as WBRT in $14 \%$ of cases, systemic therapy in $23 \%$ and combined WBRT with systemic chemotherapy in $40 \%$. Twenty-three percent of patients with multiple brain lesions received best supportive care only.

Overall survival in the entire patient collective in univariate analysis. By November 2011, 93 of the 100 patients had already died and in $84 \%$ of cases, death was related to malignant melanoma. Median follow-up in surviving patients was 32 (4-222) months and it was 3.5 (0-222) months in all patients.

Median OS (after initial diagnosis) in the entire patient collective was 3.9 months, 1-year survival rate was $21.4 \%$. Local and systemic therapy, number of brain metastases and extracranial metastasis were identified as significant predictors for OS in the entire patient collective.

Patients who received local therapy (either surgery and/or stereotactic radiotherapy) at any time had a superior OS (6.9 months, $\mathrm{n}=46$ ) compared to patients who never received 

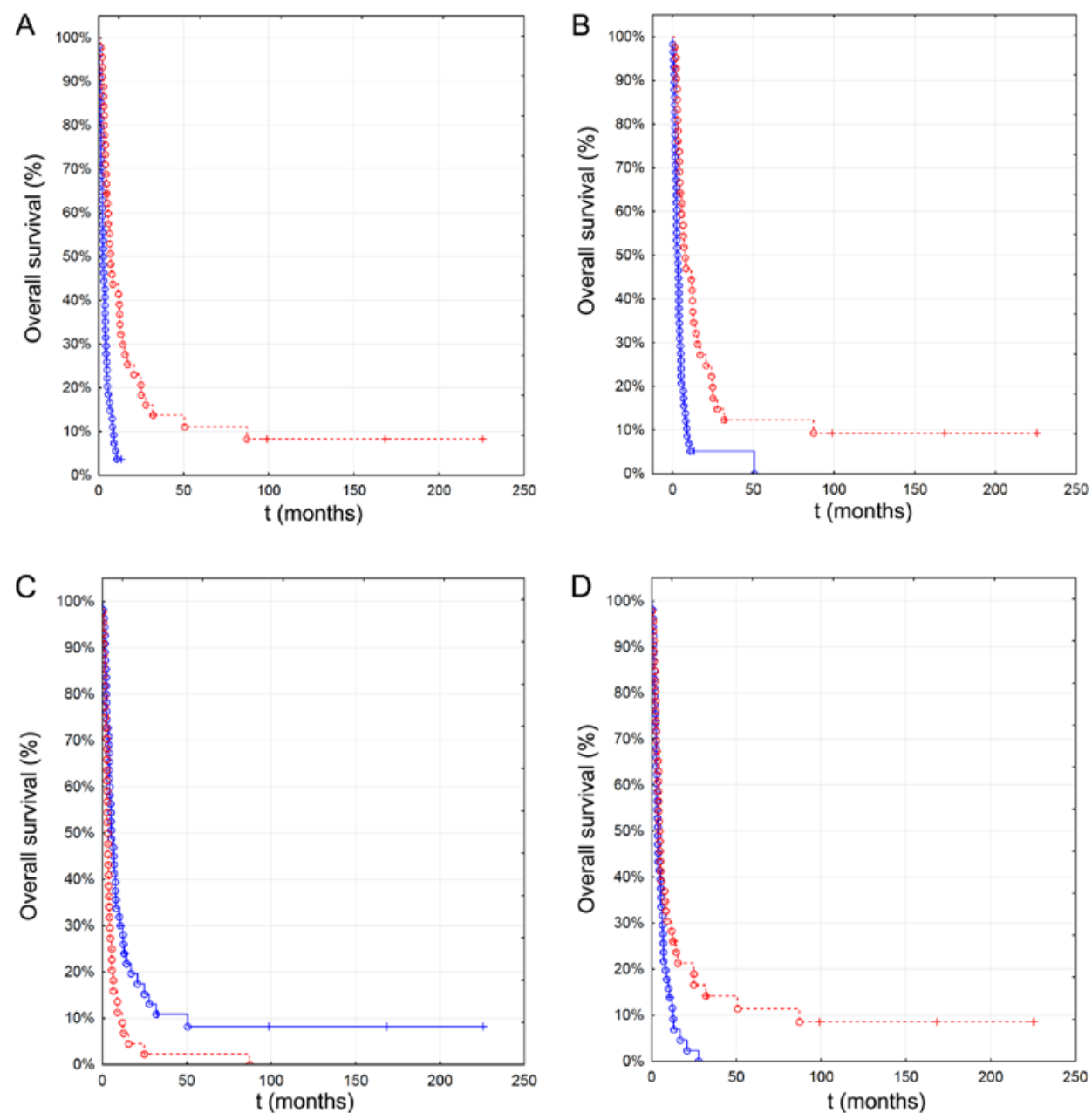

Figure 1. Association of overall survival with clinical and treatment characteristics in the primary therapy in the entire patient cohort ( $\mathrm{n}=100)$. (A) Use of any local therapy ( 6.9 months, $n=46$, blue continuous line) vs. no local therapy ( 2.6 months, $n=54$, red dotted line). (B) Use of local therapy in primary treatment ( 7.5 months, $n=42$, blue continous line) vs. no local therapy in primary treatment ( 2.8 months, $n=58$, red dashed line). (C) Use of any systemic therapy (5.1 months, $n=55$, blue continuous line) ever vs. no systemic therapy ( 3.1 months, $n=45$, red dashed line). (D) One to two brain metastasis ( 6.5 months, $n=53$, red dashed line) vs. $\geq 2$ brain metastasis ( 2.6 months, $n=47$, blue continuous line).

local therapy (2.6 months, $n=54, p<0.001)$ (Fig. 1A). Use of local therapy in the primary treatment $(n=42)$ was associated with better OS (7.5 vs. 2.8 months, p<0.001) (Fig. 1B) and use of systemic therapy resulted in a median OS of 5.1 months $(n=55)$ compared to 3.1 months without use of systemic treatment $(n=45, p=0.002)$ (Fig. 1C).

Increasing number of brain metastasis significantly reduced OS which was 6.5 months in patients with one solitary lesion $(\mathrm{n}=40), 6.4$ months in patients with 2 metastatic lesions $(\mathrm{n}=13)$, 3.8 months in those with 3 lesions $(n=7)$ and 2.5 months in patients with $>3$ brain metastases $(n=40, p<0.001)$. OS was significantly lower in patients with $>3$ metastatic brain lesions $(\mathrm{n}=47)$ compared to patients with $1-2$ lesions (2.6 vs. 6.5 months, $\mathrm{p}=0.029)$ (Fig. 1D). Patients with extracranial metastases had a median OS of 3.9 months compared to 4.4 months in patients where metastases were confined to brain $(\mathrm{p}=0.022, \mathrm{n}=71)$.

No association was determined between OS and number of extracranial metastatic sites $(\mathrm{p}=0.98)$, location of extracranial metastases $(\mathrm{p}=0.4)$, lactate dehydrogenase $(\mathrm{LDH})$ levels $(\mathrm{p}=0.11)$ and WBRT in the primary treatment concept $(\mathrm{p}=0.09)$ even though patients who received WBRT $(\mathrm{n}=45)$ lived longer than patients without WBRT (4.8 vs. 3.5 months, $\mathrm{p}=0.85$ ).

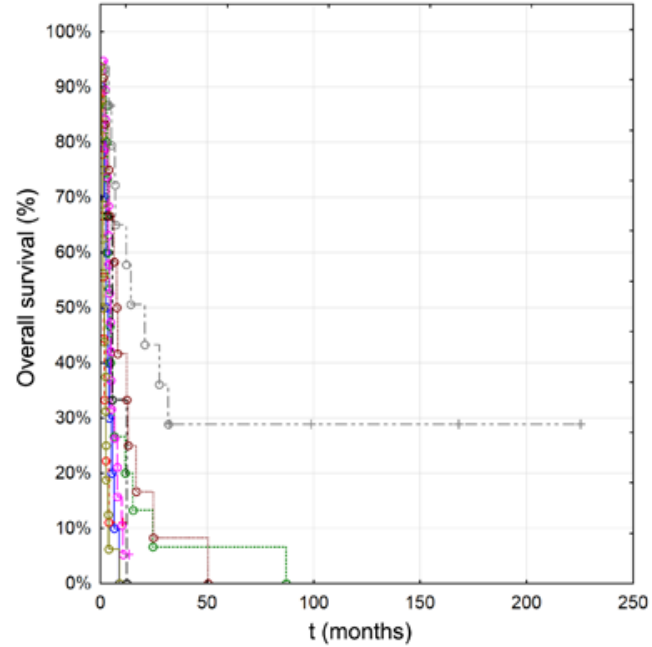

Figure 2. Overall survival according to treatment modality in the whole therapy in the entire patient cohort $(\mathrm{n}=100)$. WBRT only (median overall survival 3.2 months, $n=10$, blue continuous line), systemic therapy only (1.6 months, $n=9$, red dashed line), local therapy only ( 4.4 months, $n=16$, green dashed line), WBRT + systemic therapy ( 4.7 months, $\mathrm{n}=19$, pink dashed line), WBRT + local therapy (5.6 months, $\mathrm{n}=3$, black dashed line), systemic + local therapy (14.2 months, $\mathrm{n}=15$, grey dashed line), triple therapy (WBRT, systemic and local therapy, 8 months, $n=12$, brown dotted line) and no treatment ( 1.5 months, $\mathrm{n}=16$, olive continuous line). 
Table IV. Median OS (months) in patients with respect to therapy approach as part of primary or whole treatment concept.

\begin{tabular}{lcc}
\hline Therapy approach & $\begin{array}{c}\text { Primary } \\
\text { therapy }\end{array}$ & $\begin{array}{c}\text { Whole } \\
\text { therapy }\end{array}$ \\
\hline WBRT only & 3.2 & 3.2 \\
Systemic therapy only & 3.3 & 1.6 \\
Local therapy only & 6.4 & 4.4 \\
WBRT + systemic therapy & 4.1 & 4.7 \\
WBRT + local therapy & 8.2 & 5.6 \\
Systemic + local therapy & 12.7 & 14.2 \\
WBRT + systemic + local therapy & 2 & 8 \\
No therapy & 1.5 & 1.5 \\
\hline
\end{tabular}

Different treatment modalities yielded different OS $(p<0.001)$ depending on whether they were used in the primary treatment or whether they were part of the whole treatment (including further treatments after disease progression) (Table IV).

The subgroup which received local plus systemic therapy at any time (initial treatment or over the course of the disease) had the best OS (12.7 and 14.2 months, $n=10$ ) (Fig. 2). If triple therapy (WBRT + systemic + local therapy) was used in the primary treatment, median OS was 2 months, however, it was 8 months if all three treatment modalities were part of the whole treatment concept.

Overall survival in the entire patient collective in multivariate analysis. The following factors which were significantly associated with OS in the univariate analysis have been included in multivariate evaluation: number of brain metastases, use of local therapy in the primary treatment and presence of extracranial metastases before diagnosis of brain metastasis.

All tested variables remained independent predictors for OS and the hazard ratio for patients with $>2$ brain metastases was 2.2 compared to patients with 1-2 cerebral metastases $(\mathrm{p}=0.0005)$. Patients who did not receive local therapy in their primary treatment had an increased risk of death by a factor 1.8 as opposed to patients with local therapy $(\mathrm{p}=0.035)$ and patients with metastases confined to the brain were less likely to die $(H R=0.6, p=0.035)$ compared to patients with additional extracranial metastasis.

OS in patients with multiple cranial metastases. The subgroup of patients with multiple brain metastases $(n=35)$ contains all patients who were initially diagnosed with multiple brain metastases or who developed multiple brain metastases during their disease course. OS in patients only receiving systemic treatment was 1.8 months and it was 1.5 months in patients under best supportive care.

The whole treatment (including sequential modalities after disease progression) significantly influenced OS in this subgroup ( $p=0.007)$ : the best OS in patients with multiple brain metastases could be achieved if WBRT was combined with systemic treatment (median OS 3.8 months) in the

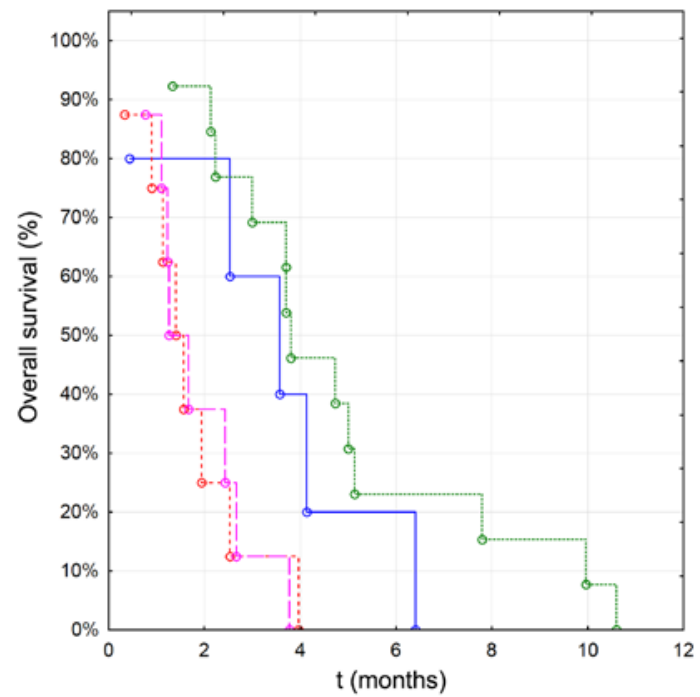

Figure 3. Overall survival in patients with multiple brain metastasis $(n=35)$ according to treatment modality in overall therapy. WBRT only (median 3.6 months, $n=5$, blue continuous line), systemic therapy ( 1.5 months, $n=8$, red dashed line), WBRT + systemic therapy ( 3.8 months, $n=14$, green dashed libe) and no therapy ( 1.5 months, $\mathrm{n}=8$, pink dashed line).

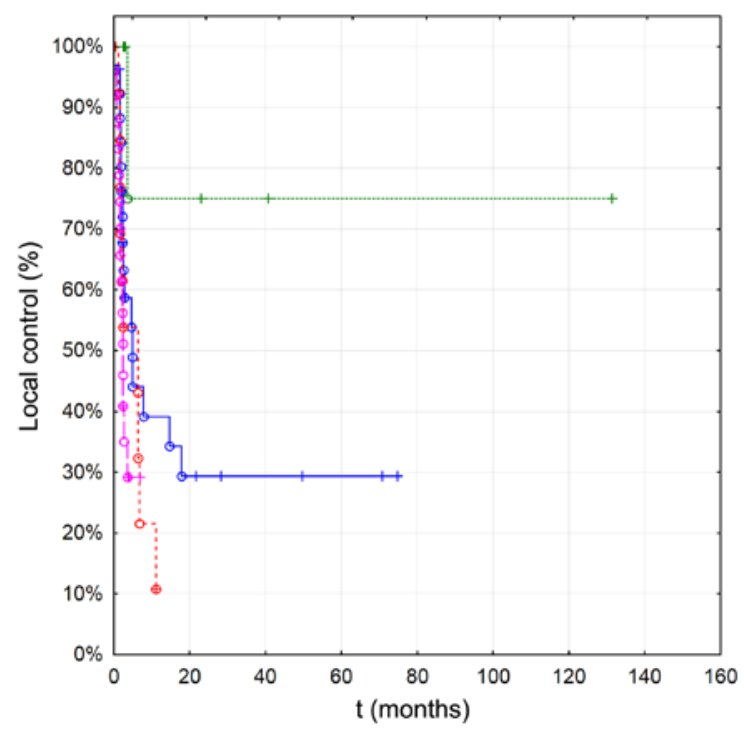

Figure 4. Local control in single brain metastasis $(n=35)$ according to local treatment modality in the primary therapy $(n=72)$. Surgery only (median 2.8 months, $n=27$, blue continuous line), stereotactic radiotherapy only ( 2.5 months, $n=14$, red dashed line), stereotactic radiotherapy + surgery (13.2 months, $n=6$, green dashed line) and no therapy ( 2 months, $n=25$, pink dashed line).

primary treatment compared to WBRT alone (3.6 months). However, the survival difference between these two groups was rather small and the findings did not reach statistical significance $(\mathrm{p}=0.058)$. Patients treated with systemic therapy only or no therapy at all had a similar median OS of 1.5 months (Fig. 3).

Tumor control in relation to different treatment modalities. In the entire patient cohort, intracranial tumor control could be evaluated in 58 patients. The intracranial disease course 
Table V. Association of different treatment modalities and local tumor control per lesion ( $\mathrm{n}=37$ patients, $\mathrm{n}=72$ lesions).

\begin{tabular}{|c|c|c|c|}
\hline Therapy approach & Metastases n (\%) & Median LC (months) & p-value (log-rank) \\
\hline \multicolumn{4}{|l|}{ Primary therapy $(n=72)$} \\
\hline WBRT only & $8(11)$ & 3 & 0.011 \\
\hline Systemic therapy only & $14(20)$ & 2 & \\
\hline Local therapy only & $31(44)$ & 2.7 & \\
\hline WBRT + systemic therapy & $3(4)$ & 2 & \\
\hline Local therapy + WBRT & $6(9)$ & 2 & \\
\hline Systemic + local therapy & $8(11)$ & 11.1 & \\
\hline \multicolumn{4}{|l|}{ Surgery as primary therapy $(n=72)$} \\
\hline Yes & $33(46)$ & 3 & 0.021 \\
\hline No & $39(54)$ & 2.3 & \\
\hline \multicolumn{4}{|c|}{ Local therapy in primary treatment $(n=72)$} \\
\hline Surgery & $27(38)$ & 2.8 & 0.042 \\
\hline Stereotactic radiotherapy & $14(19)$ & 2.5 & \\
\hline Surgery + stereotactic radiotherapy & $6(9)$ & 13.2 & \\
\hline No local therapy & $25(35)$ & 2 & \\
\hline
\end{tabular}

was significantly associated with OS $(\mathrm{p}=0.0037)$ and intracranial tumor control (until last follow-up) was documented in 28 patients. In 42 patients, no follow-up data on tumor control was available. Median OS in patients with controlled tumors was 10 months compared to 5 months in patients with intracranial tumor progression $(n=30, p=0.004)$.

For the subgroup of patients with multiple brain metastases, no significant association between the two most commonly performed primary therapies (combined WBRT with systemic therapy and systemic therapy only) and intracranial tumor control $(p=0.23)$ could be determined.

When 72 brain metastases from 37 patients were evaluated for LC per lesion, 50\% remained locally controlled and 50\% were progressive after a median time interval of 3.6 months. In this group, the primary treatment modality was significantly associated with LC which was best after a combination of local therapy plus systemic therapy in the primary treatment $(\mathrm{p}=0.011)($ Table V).

Metastases which were treated primarily surgically $(n=33)$ showed a median LC of 2.96 months compared to 2.33 months in metastases where surgery was not used in the primary treatment $(\mathrm{p}=0.021)$ (Table V).

Use of local therapy approaches in the primary therapy was also associated with LC (Fig. 4): 6-month LC was $75 \%$ when surgery was combined with stereotactic radiotherapy (median LC 13.2 months, Table V), it was 53\% in the stereotactic radiotherapy only group and $43 \%$ in the surgery only group $(\mathrm{p}=0.042)$.

\section{Discussion}

The aim of this study was to identify prognostic factors for survival in stage IV melanoma patients with brain metastasis. Similar to prior studies, this study is retrospective (37-39) which underlines the need for confirmation of our findings in prospective randomized trials.
Predictors for OS in patients with malignant melanoma metastatic to the brain have been published previously and include LDH levels, age, Karnofsky index, number of brain metastasis, leptomeningeal spread, presence of extracerebral metastases, melanoma ulceration, histology and neurologic symptoms $(10,13,18,25,37,39-42)$.

The present analysis however, additionally focused on the subgroup of patients with multiple brain metastases and evaluated tumor control with respect to different treatment modalities.

Male gender in our study was more frequent than female gender (65 vs. $35 \%$ ) which is similar to the gender distribution in other reports $(10,17,37,39,43)$. Unlike the study of Hofmann et $a l$, we did not find a significant influence of gender on survival (44). Median age at the time of initial diagnosis of malignant melanoma was 57 years in our cohort which is slightly higher compared to other studies $(10,42)$ which may be attributed to the relatively small patient number $(n=100)$ and long investigation period (1992-2011) in our study. Fife et al reported a median age at the time of diagnosis of brain metastasis of 49 and 57 years with a median time from initial diagnosis of melanoma until occurrence of cerebral metastasis of 2.5 and 3.7 years (10). In our study, patients were older when brain metastasis was confirmed (62 years), however, median time to development of cerebral metastasis (2.5 years in our patient group) was comparable with current literature (1.9-2.7 years) $(17,18,37,39)$.

The impact of age on OS in melanoma patients with brain metastasis has been reported by several studies $(10,18,39,40)$ but could not be replicated in our study.

Nodular melanoma was most frequently diagnosed in our patient cohort (42\%) and extracranial metastases were present in the majority of patients $(71 \%)$. In the literature, extracranial metastatic involvement is reported in $65-83 \%(10,37,39,43,45)$ of patients and in $37-51 \%$ of cases, multiple organ systems are affected by extracerebral metastasis $(10,37)$. 
In $22 \%$ of the patients in our study, lymph nodes were positive for metastasis upon initial diagnosis of melanoma and $61 \%$ of patients developed metastatic spread to lymphatic nodes during their disease course which stands in line with current literature, reporting lymph node metastasis in $24-54 \%(17,39)$.

Our own results registered multiple site involvement in $65 \%$ of melanoma patients and in $71 \%$ of the patients, brain metastases were symptomatic which is in accordance with the findings of Raizer et al (39) and Mornex et al (45) who reported neurological symptoms from brain metastasis in $66-85 \%$ of patients.

Compared to other relevant reports which included 17-67\% patients with multiple brain metastases $(10,37,39,43,45)$, the proportion of patients with multiple brain metastases in this study was $35 \%$.

Median survival in our study was 3.9 months which is shorter compared to other relevant studies in this field $(10,17,18,37,39,41)$. Moreover, the majority of our patients displayed extracranial metastasis and was diagnosed with nodular type melanoma which was associated with a considerably poor prognosis. In our collective, seven long-term survivors could be indentified with a median survival of 32 months.

Number of brain metastasis, presence of extracranial metastasis and extracranial disease progression but not LDH levels were significantly associated with survival. Two large retrospective studies $(37,40)$ reported $\mathrm{LDH}$ levels to be related to survival.

Fifty-three percent of patients in our study had 1-2 brain metastases and lived 6.5 months compared to patients with $>2$ cerebral metastases who had a median survival of 2.5 months which is accordance with current literature $(10,37,39,40)$ : Liew et al (46) reported a superior survival of patients with 1-3 brain metastases compared to $>4$ metastatic brain lesions after stereotactic radiotherapy and Staudt et al (40) showed a median survival of 8 months in patients with a solitary brain lesion as opposed to 3 months in patients with multiple brain metastases. In the cohort of Eigentler et al (37) patients with multiple brain metastases had a significantly inferior survival compared to those with one single brain metastasis and Raizer et al (39) reported extracranial disease and number of brain metastasis to significantly reduce OS (8 months with single vs. 3 months with multiple brain metastases). Interestingly, we could replicate the finding of Raizer et al (39) that $>3$ cranial metastases critically reduced OS.

A significant impact of neurologic symptoms on OS, which was reported by Bottoni et al (17) and Raizer et al (39), could not be demonstrated by our study $(\mathrm{p}=0.52)$.

Our findings furthermore indicate that location of metastasis did not impact OS, contrasting the results of Wronski and Arbit (43) who reported the infratentorial location to be associated with a significantly reduced OS in a series of surgically treated stage IV melanoma patients.

Untreated patients with brain metastasis from malignant melanoma have a poor prognosis with an expected median survival of only 1-3 months $(47,48)$ which accentuates palliation, quality of life and tumor control as the main treatment focus in stage IV malignant melanoma $(49,50)$.

Surgical treatment is indicated if pathological confirmation of a cerebral mass is needed and quick symptom relief from a single dominant lesion is necessary, especially when obstructive symptoms (i.e., hydrocephalus) or mass effects (i.e., midline shift, bleeding) are present (22) and has been shown to improve local control and survival $(10,37,51)$. Despite its applicability to differently sized lesions, the surgical approach is limited to accessible intracerebral lesions.

Radiosurgery may be suitable for patients with limited size and number of cerebral lesions (particularly those $<3 \mathrm{~cm}$ in size and with mild edema and no mass effect) but in principle is feasible for brain lesions irrespective of their location (7,11-13,22,52-54) with a low complication rate, mortality and morbidity $(50,52)$. Evidence supports the equivalence of stereotactic radiotherapy and surgery in the treatment of solitary metastatic cerebral lesions with a reported 1-year local control rate of $82 \%$ after stereotactic radiotherapy (55).

The rationale for WBRT in the adjuvant setting (i.e., after local therapy or in inoperable patients who are also no candidates for stereotactic radiotherapy) is to treat microscopic disease in order to improve tumor control and possibly survival $(13,56,57)$. Compared to untreated patients, WBRT improves survival and may mitigate neurologic symptoms $(30,52,58)$ but so far, a significant survival benefit from WBRT could not be demonstrated $(10,22,59,60)$.

For decades, most cytotoxic drugs which were available for treatment of metastatic melanoma failed to significantly improve survival. Little progress could be achieved when the cytokines interleukin and interferon became available in the late 1990s while later, cytotoxic drugs such as fotemustine and temozolomide which pass the blood-brain barrier were routinely used in malignant melanoma metastatic to the brain $(61,62)$, yielding response rates of only $25-30 \%$ (fotemustine) and $5-17 \%$ (temozolomide) $(23,45,63,64)$. Combination of radiation with chemotherapy also did not lead to a significant improvement in survival with response rates of $7.6 \%$ and a median time to progression of only 7 weeks $(15-18,22)$. Additional use of steroids showed symptom relief and proved to be superior to best supportive care $(22,37)$.

However, with the approval of new systemic agents in 2011, including immunomodulators such as ipilimumab, a monoclonal antibody targeting CTLA-4 ligand, considerable progress in the treatment of advanced melanoma could be achieved $(65,66)$. Using vermurafinib, a BRAF-inhibitor, in patients with BRAF-mutated melanoma for instance, resulted in significantly improved overall and progression-free survival (67-69). Also other members of recently (2013) approved drugs such as Dabrafenib and Trametinib showed promising results in phase III trials so that the portfolio of systemic targeted drugs which can be used as standard therapy for metastatic melanoma has been expanded considerably (70).

In a large cohort of 686 patients with brain metastasis from malignant melanoma, Fife et al (10) reported a superior survival if surgery was followed by radiotherapy $(24 \%$, 8.9 months) or surgery was given alone (7\%, 8.7 months) compared to radiotherapy alone (36\%, 3.4 months). Wronski and Arbit (43) found that consecutive WBRT after surgical resection of brain metastasis did not improve OS and recurrence rates. In our study, OS in patients treated with WBRT alone was 3.2 months which is comparable with the study of Fife et al (10). Median survival of patients who received local therapy (either surgery or stereotactic radiotherapy) followed 
by WBRT was 8.2 months and the best OS could be achieved if local therapy was combined with systemic therapy in the primary treatment (12.7 months).

In the study of Raizer et al, surgery (9.3 vs. 3.9 months), systemic therapy (7.9 vs. 4.1 months) and stereotactic radiotherapy (10 vs. 4.3 months) but not WBRT significantly improved survival (39). These results are supported by our own findings, indicating a superior survival in patients who received systemic (5.1 vs. 3.1 months, $\mathrm{p}<0.002$ ) and local therapy (either stereotactic radiotherapy or surgery, 6.9 vs. 2.6 months, $\mathrm{p}<0.001)$. The finding that WBRT non-significantly prolongs OS could also be replicated (4.8 vs. 3.5 months, $\mathrm{p}=0.85$ ) by our study.

Raizer et al reported the best OS if surgery was combined with stereotactic radiotherapy (13.2 months), followed by the triple combination of surgery, stereotactic radiotherapy and WBRT (10.2 months) (39). In our study, the triple therapy (WBRT, local and systemic therapy) yielded a median OS of 2 months (primary therapy) and 8 months (whole treatment) and the best OS could be achieved with the combination of systemic and local therapy (12.7 months as primary therapy, 14.2 months as part of the whole treatment concept). Notably, the study of Raizer et al (39) included 355 patients and systemic therapy was not evaluated in the combination therapy.

Surgery or stereotactic radiotherapy alone was reported with a median OS of 8.2 and 9.9 months in the study of Raizer et al (39). Here, we found that use local therapy (surgery or stereotactic radiotherapy) was associated with a median survival of 6.4 (primary therapy) and 4.4 months (whole therapy). As evidenced by the current literature, local therapy (stereotactic radiotherapy or surgery) and systemic therapy remain independent predictors for OS in the treatment of single brain metastasis $(37,39)$.

For patients with multiple brain metastases, we found that the combination of WBRT and systemic treatment resulted in a marginally superior OS compared to WBRT alone (+0.2 months) which stands in line with current literature $(71,72)$.

We demonstrated that the intracranial disease course is significantly associated with OS $(\mathrm{p}=0.0037)$ and that patients with intracranial tumor control achieved a better OS (10 months) compared to patients with uncontrolled intracerebral situation (5 months) which supports current studies showing a correlation between intracranial tumor control and prolonged survival $(37,40,49)$. If surgery was followed by stereotactic radiotherapy, intracranial tumor control in our study was superior which supports current literature, reporting local control rates between $84-94 \%$ after combined surgery and stereotactic radiotherapy (73-75).

In our study, use of local therapy in the primary treatment significantly increased LC per lesion $(p=0.042)$ which was best in patients who were treated with a combination of local and systemic therapy.

When interpreting the results of this study, some limitations need to be discussed. Our study was of retrospective design with all limitations inherent to such studies.

Since patients from 1992 up to 2011 were included in the study, recent developments (i.e., after 2011) in the treatment of stage IV malignant melanoma, particularly the use of new systemic agents such as BRAF and MEK targeted drugs or
CTLA4 and PD1 immune checkpoint modulators which were approved by the FDA in 2011 could not be incorporated in this study. Thus, the significant therapeutic advances achieved by the standard use of these drugs (76) is not mirrored in this study which limits the ability of our results to impact on current treatment or management strategies.

Furthermore, a heterogeneous patient collective where treatment modalities varied was analyzed and information regarding causes of death was not routinely available. Thus, no causal relation between therapies and survival could be determined by our study.

Also, data on Karnofsky performance score (KPS) and S100B value were insufficient so that both GPA and RPA scores $(37,40)$ could not be acquired and multivariate analyses could not be adjusted for KPS. Therefore, the impact of the aforementioned parameters on OS could not be evaluated in our study which limits concrete conclusions of the effect on OS that each variable may have. It is conceivable that use of local therapy may be a surrogate for KPS in the dataset presented in this study.

Finally, analyses regarding the treatments given could have generated selection effects since only patients who lived long enough could receive more than one treatment modality. With respect to the different treatment arms, selection bias cannot be excluded since only patients with good performance status and little comorbidity were candidates for surgery for instance.

In conclusion, number of brain metastasis $(\mathrm{p}=0.004)$, presence of extracranial metastases $(p=0.035)$ and use of local therapy in the primary treatment $(\mathrm{p}=0.035)$ are independent predictors for survival in patients with brain metastases from malignant melanoma.

For patients with single brain metastasis, a survival benefit could be demonstrated for local therapy approaches and systemic treatment but not for WBRT.

Intracranial tumor control (per patient) is prognostic in malignant melanoma metastatic to the brain. LC (per lesion) and OS can be most considerably improved by combining local with systemic therapy. Surgical metastasectomy followed by stereotactic radiotherapy can increase LC. Patients with multiple brain metastases benefit from slightly improved OS after a combination of systemic therapy with WBRT.

\section{Acknowledgements}

We would like to thank our colleagues from the Department of Radiation Oncology and the Department of Dermatology for their contribution to this study and their continuous support.

\section{References}

1. Galicich JH: Metastatic brain tumors. In: Neurosurgery. Vol. 1. 2nd edition. Wilkins RH and Rengachary SS (eds). McGraw-Hill, New York, NY, pp807-821, 1996.

2. Nussbaum ES, Djalilian HR, Cho KH and Hall WA: Brain metastases. Histology, multiplicity, surgery, and survival. Cancer 78: 1781-1788, 1996.

3. Patchell RA: Metastatic brain tumors. Neurol Clin 13: 915-925, 1995.

4. Johnson JD and Young B: Demographics of brain metastasis. Neurosurg Clin North Am 7: 337-344, 1996. 
5. Presant CA and Bartolucci AA: Prognostic factors in metastatic malignant melanoma: The Southeastern Cancer Study Group Experience. Cancer 49: 2192-2196, 1982.

6. Balch CM and Houghton AN: Diagnosis of metastatic melanoma at distant sites. In: Cutaneous Melanoma. Vol. 1. 1st edition. Balch CM, Houghton AN, Milon GW, Sober AJ and Soong SJ (eds). Lippincott, Philadelphia, PA, pp439-467, 1992.

7. Sampson JH, Friedman AH and Seigler HF: Demographics, treatment, and prognosis of 76 patients with 'primary' intracerebral melanoma. J Neurosurg 82: A357, 1995.

8. Moon D, Maafs E, Peterson-Schaefer K, et al: A review of 567 cases of brain metastases from malignant melanoma. Melanoma Res 3: 40, 1993.

9. Bhatia S, Tykodi SS and Thompson JA: Treatment of metastatic melanoma: An overview. Oncology (Williston Park) 23: 488-496, 2009.

10. Fife KM, Colman MH, Stevens GN, Firth IC, Moon D, Shannon KF, Harman R, Petersen-Schaefer K, Zacest AC, Besser M, et al: Determinants of outcome in melanoma patients with cerebral metastases. J Clin Oncol 22: 1293-1300, 2004.

11. Buchsbaum JC, Suh JH, Lee SY, Chidel MA, Greskovich JF and Barnett GH: Survival by radiation therapy oncology group recursive partitioning analysis class and treatment modality in patients with brain metastases from malignant melanoma: A retrospective study. Cancer 94: 2265-2272, 2002

12. Saha S, Meyer M, Krementz ET, Hoda S, Carter RD, Muchmore J and Sutherland C: Prognostic evaluation of intracranial metastasis in malignant melanoma. Ann Surg Oncol 1: 38-44, 1994.

13. Sampson JH, Carter JH Jr, Friedman AH and Seigler HF: Demographics, prognosis, and therapy in 702 patients with brain metastases from malignant melanoma. J Neurosurg 88: 11-20, 1998.

14. de la Monte SM, Moore GW and Hutchins GM: Patterned distribution of metastases from malignant melanoma in humans. Cancer Res 43: 3427-3433, 1983

15. Patel JK, Didolkar MS, Pickren JW and Moore RH: Metastatic pattern of malignant melanoma. A study of 216 autopsy cases. Am J Surg 135: 807-810, 1978.

16. Amer MH, Al-Sarraf M, Baker LH and Vaitkevicius VK: Malignant melanoma and central nervous system metastases: Incidence, diagnosis, treatment and survival. Cancer 42: 660-668, 1978.

17. Bottoni U, Clerico R, Paolino G, Ambrifi M, Corsetti P and Calvieri S: Predictors and survival in patients with melanoma brain metastases. Med Oncol 30: 466, 2013.

18. Zakrzewski J, Geraghty LN, Rose AE, Christos PJ, Mazumdar M, Polsky D, Shapiro R, Berman R, Darvishian F, Hernando E, et al: Clinical variables and primary tumor characteristics predictive of the development of melanoma brain metastases and post-brain metastases survival. Cancer 117: 1711-1720, 2011.

19. Jakob JA, Bassett RL Jr, Ng CS, Curry JL, Joseph RW, Alvarado GC, Rohlfs ML, Richard J, Gershenwald JE, Kim KB et al: NRAS mutation status is an independent prognostic factor in metastatic melanoma. Cancer 118: 4014-4023, 2012.

20. McLoughlin JM, Zager JS, Sondak VK and Berk LB: Treatment options for limited or symptomatic metastatic melanoma. Cancer Control 15: 239-247, 2008 .

21. Carella RJ, Gelber R, Hendrickson F, Berry HC and Cooper JS: Value of radiation therapy in the management of patients with cerebral metastases from malignant melanoma: Radiation Therapy Oncology Group Brain Metastases Study I and II Cancer 45: 679-683, 1980.

22. Hong A, Fogarty G and Izard MA: The role of radiation therapy in the management of metastatic melanoma in the brain. Int J Surg Oncol 2012: 294735, 2012.

23. Jacquillat C, Khayat D, Banzet P, Weil M, Fumoleau P, Avril MF Namer M, Bonneterre J, Kerbrat P, Bonerandi JJ, et al: Final report of the French multicenter phase II study of the nitrosourea fotemustine in 153 evaluable patients with disseminated malignant melanoma including patients with cerebral metastases. Cancer 66: 1873-1878, 1990.

24. Jacquillat C, Khayat D, Banzet $P$, Weil M, Avril MF, Fumoleau P, Namer M, Bonneterre J, Kerbrat $\mathrm{P}$, Bonerandi JJ, et al: Chemotherapy by fotemustine in cerebral metastases of disseminated malignant melanoma. Cancer Chemother Pharmacol 25: 263-266, 1990.

25. Mori Y, Kondziolka D, Flickinger JC, Kirkwood JM, Agarwala S and Lunsford LD: Stereotactic radiosurgery for cerebral metastatic melanoma: Factors affecting local disease control and survival. Int J Radiat Oncol Biol Phys 42: 581-589, 1998.
26. Overett TK and Shiu MH: Surgical treatment of distant metastatic melanoma. Indications and results. Cancer 56: 1222-1230, 1985.

27. Zacest AC, Besser M, Stevens G, Thompson JF, McCarthy WH and Culjak G: Surgical management of cerebral metastases from melanoma: Outcome in 147 patients treated at a single institution over two decades. J Neurosurg 96: 552-558, 2002.

28. Houghton AN: Treatment for advanced melanoma. In: Cutaneous Melanoma. Vol. 1. 1st edition. Balch CM, Houghton AN, Milon GW, Sober AJ and Soong SJ (eds). Lippincott, Philadelphia, PA, pp468-497, 1992.

29. Ellerhorst J, Strom E, Nardone E and McCutcheon I: Whole brain irradiation for patients with metastatic melanoma: A review of 87 cases. Int J Radiat Oncol Biol Phys 49: 93-97, 2001.

30. Morris SL, Low SH, A'Hern RP, Eisen TG, Gore ME, Nutting CM and Harrington KJ: A prognostic index that predicts outcome following palliative whole brain radiotherapy for patients with metastatic malignant melanoma. Br J Cancer 91: 829-833, 2004.

31. Gupta G, Robertson AG and MacKie RM: Cerebral metastases of cutaneous melanoma. Br J Cancer 76: 256-259, 1997.

32. Vlock DR, Kirk wood JM, Leutzinger C, Kapp DS and Fischer JJ: High-dose fraction radiation therapy for intracranial metastases of malignant melanoma: A comparison with low-dose fraction therapy. Cancer 49: 2289-2294, 1982.

33. Stridsklev IC, Hagen S and Klepp O: Radiation therapy for brain metastases from malignant melanoma. Acta Radiol Oncol 23: 231-235, 1984.

34. Madajewicz S, Karakousis C, West CR, Caracandas J and Avellanosa AM: Malignant melanoma brain metastases. Review of Roswell Park Memorial Institute experience. Cancer 53: 2550-2552, 1984.

35. Douglas JG and Margolin K: The treatment of brain metastases from malignant melanoma. Semin Oncol 29: 518-524, 2002

36. McWilliams RR, Brown PD, Buckner JC, Link MJ and Markovic SN: Treatment of brain metastases from melanoma. Mayo Clin Proc 78: 1529-1536, 2003.

37. Eigentler TK, Figl A, Krex D, Mohr P, Mauch C, Rass K, Bostroem A, Heese O, Koelbl O, Garbe C, et al: Dermatologic Cooperative Oncology Group and the National Interdisciplinary Working Group on Melanoma: Number of metastases, serum lactate dehydrogenase level, and type of treatment are prognostic factors in patients with brain metastases of malignant melanoma. Cancer 117: 1697-1703, 2011.

38. Grob JJ, Regis J, Laurans R, Delaunay M, Wolkenstein P, Paul K, Souteyrand P, Koeppel MC, Murraciole X, Perragut JC, et al: Radiosurgery without whole brain radiotherapy in melanoma brain metastases. Club de Cancérologie Cutanée. Eur J Cancer 34: 1187-1192, 1998

39. Raizer JJ, Hwu WJ, Panageas KS, Wilton A, Baldwin DE, Bailey E, von Althann C, Lamb LA, Alvarado G, Bilsky MH, et al: Brain and leptomeningeal metastases from cutaneous melanoma: Survival outcomes based on clinical features. Neurooncol 10: 199-207, 2008

40. Staudt M, Lasithiotakis K, Leiter U, Meier F, Eigentler T, Bamberg M, Tatagiba M, Brossart P and Garbe C: Determinants of survival in patients with brain metastases from cutaneous melanoma. Br J Cancer 102: 1213-1218, 2010.

41. Davies MA, Liu P, McIntyre S, Kim KB, Papadopoulos N, Hwu WJ, Hwu P and Bedikian A: Prognostic factors for survival in melanoma patients with brain metastases. Cancer 117: 1687-1696, 2011.

42. Eisemann N, Jansen L, Holleczek B, Waldmann A, Luttmann S, Emrich K, Hauschild A, Brenner H and Katalinic A; GEKID Survival Working Group: Up-to-date results on survival of patients with melanoma in Germany. Br J Dermatol 167: 606-612, 2012.

43. Wroński M and Arbit E: Surgical treatment of brain metastases from melanoma: A retrospective study of 91 patients. J Neurosurg 93: 9-18, 2000

44. Hofmann M, Kiecker F, Wurm R, Schlenger L, Budach V, Sterry W and Trefzer U: Temozolomide with or without radiotherapy in melanoma with unresectable brain metastases. J Neurooncol 76: 59-64, 2006.

45. Mornex F, Thomas L, Mohr P, Hauschild A, Delaunay MM, Lesimple T, Tilgen W, Bui BN, Guillot B, Ulrich J, et al: A prospective randomized multicentre phase III trial of fotemustine plus whole brain irradiation versus fotemustine alone in cerebral metastases of malignant melanoma. Melanoma Res 13: 97-103, 2003. 
46. Liew DN, Kano H, Kondziolka D, Mathieu D, Niranjan A Flickinger JC, Kirkwood JM, Tarhini A, Moschos S and Lunsford LD: Outcome predictors of Gamma Knife surgery for melanoma brain metastases. Clinical article. J Neurosurg 114: 769-779, 2011.

47. Garbe C, Hauschild A, Volkenandt M, Schadendorf D, Stolz W, Reinhold U, Kortmann RD, Kettelhack C, Frerich B, Keilholz U, et al: Evidence and interdisciplinary consensus-based German guidelines: Surgical treatment and radiotherapy of melanoma. Melanoma Res 18: 61-67, 2008.

48. Sloan AE, Nock CJ and Einstein DB: Diagnosis and treatment of melanoma brain metastasis: A literature review. Cancer Control 16: 248-255, 2009.

49. Steinbach J, Vordermark D and Gutzmer R: ZNS-Metastasen eine interdisziplinäre Herausforderung. Onkologie 36 (Suppl 4): 2-6, 2013 (In German)

50. Flanigan JC, Jilaveanu LB, Chiang VL and Kluger HM: Advances in therapy for melanoma brain metastases. Clin Dermatol 31: 264-281, 2013

51. Miller D, Zappala V, El Hindy N, Livingstone E, Schadendorf D Sure U and Sandalcioglu IE: Intracerebral metastases of malignant melanoma and their recurrences - a clinical analysis. Clin Neurol Neurosurg 115: 1721-1728, 2013.

52. Hanson PW, Elaimy AL, Lamoreaux WT, Demakas JJ, Fairbanks RK, Mackay AR, Taylor B, Cooke BS, Thumma SR and Lee CM: A concise review of the efficacy of stereotactic radiosurgery in the management of melanoma and renal cell carcinoma brain metastases. World J Surg Oncol 10: 176, 2012.

53. Fogarty GB and Hong A: Radiation therapy for advanced and metastatic melanoma. J Surg Oncol 109: 370-375, 2014

54. Shaw E, Scott C, Souhami L, Dinapoli R, Kline R, Loeffler J and Farnan N: Single dose radiosurgical treatment of recurrent previously irradiated primary brain tumors and brain metastases: Final report of RTOG protocol 90-05. Int J Radiat Oncol Bio Phys 47: 291-298, 2000.

55. Swinson BM and Friedman WA: Linear accelerator stereotactic radiosurgery for metastatic brain tumors: 17 years of experience at the University of Florida. Neurosurgery 62: 1018-1032, 2008.

56. Eichler AF and Loeffler JS: Multidisciplinary management of brain metastases. Oncologist 12: 884-898, 2007.

57. Kocher M, Soffietti R, Abacioglu U, Villà S, Fauchon F, Baumert BG, Fariselli L, Tzuk-Shina T, Kortmann RD, Carrie C, et al: Adjuvant whole-brain radiotherapy versus observation after radiosurgery or surgical resection of one to three cerebral metastases: Results of the EORTC 22952-26001 study. J Clin Oncol 29: 134-141, 2011.

58. Fonkem E, Uhlmann EJ, Floyd SR, Mahadevan A, Kasper E, Eton $\mathrm{O}$ and Wong ET: Melanoma brain metastasis: Overview of current management and emerging targeted therapies. Expert Rev Neurother 12: 1207-1215, 2012 .

59. Hagen NA, Cirrincione C, Thaler HT and DeAngelis LM: The role of radiation therapy following resection of single brain metastasis from melanoma. Neurology 40: 158-160, 1990.

60. Schild SE, Behl D, Markovic SN, Brown PD, Sande JR, Deming RL, Rowland KM Jr and Bearden JD: Brain metastases from melanoma: Is there a role for concurrent temozolomide in addition to whole brain radiation therapy? Am J Clin Oncol 33: 633-636, 2010
61. Gibney GT, Forsyth PA and Sondak VK: Melanoma in the brain Biology and therapeutic options. Melanoma Res 22: 177-183, 2012.

62. Lyle M and Long GV: The role of systemic therapies in the management of melanoma brain metastases. Curr Opin Oncol 26: 222-229, 2014.

63. Bafaloukos D, Tsoutsos D, Fountzilas G, Linardou H, Christodoulou C, Kalofonos HP, Briassoulis E, Panagiotou $\mathrm{P}$, Hatzichristou $\mathrm{H}$ and Gogas $\mathrm{H}$ : The effect of temozolomidebased chemotherapy in patients with cerebral metastases from melanoma. Melanoma Res 14: 289-294, 2004.

64. Schadendorf D, Hauschild A, Ugurel S, Thoelke A, Egberts F, Kreissig M, Linse R, Trefzer U, Vogt $\mathrm{T}$, Tilgen $\mathrm{W}$, et al: Dose-intensified bi-weekly temozolomide in patients with asymptomatic brain metastases from malignant melanoma: A phase II DeCOG/ADO study. Ann Oncol 17: 1592-1597, 2006.

65. Eggermont AM and Robert C: New drugs in melanoma: it's a whole new world. Eur J Cancer 47: 2150-2157, 2011.

66. Lipson EJ and Drake CG: Ipilimumab: An anti-CTLA-4 antibody for metastatic melanoma. Clin Cancer Res 17: 6958-6962, 2011

67. Spagnolo F and Queirolo P: Upcoming strategies for the treatment of metastatic melanoma. Arch Dermatol Res 304: 177-184, 2012.

68. Ravan MC and Matalke MS: Vemurafinib in patients with BRAF V600E mutation-positive advanced melanoma. Clin Ther 34: 1474-1486, 2012

69. Keating GM: Vemurafinib: in unresectable or metastatic melanoma. BioDrugs 26: 325-334, 2012.

70. Palathinkal DM, Sharma TR and Koon HB: Current systemic therapies for melanoma. Dermatol Surg 40: 948-963, 2014.

71. Margolin K, Atkins B, Thompson A, Ernstoff S, Weber J, Flaherty L, Clark I, Weiss G, Sosman J, II Smith W, et al: Temozolomide and whole brain irradiation in melanoma metastatic to the brain: A phase II trial of the Cytokine Working Group. J Cancer Res Clin Oncol 128: 214-218, 2002.

72. Atkins MB, Sosman JA, Agarwala S, Logan T, Clark JI, Ernstoff MS, Lawson D, Dutcher JP, Weiss G, Curti B, et al: Temozolomide, thalidomide, and whole brain radiation therapy for patients with brain metastasis from metastatic melanoma: A phase II Cytokine Working Group study. Cancer 113: 2139-2145, 2008.

73. Hartford AC, Paravati AJ, Spire WJ, Li Z, Jarvis LA, Fadul CE, Rhodes CH, Erkmen K, Friedman J, Gladstone DJ, et al: Postoperative stereotactic radiosurgery without whole-brain radiation therapy for brain metastases: Potential role of preoperative tumor size. Int J Radiat Oncol Biol Phys 85: 650-655, 2013.

74. Kelly PJ, Lin YB, Yu AY, Alexander BM, Hacker F, Marcus KJ and Weiss SE: Stereotactic irradiation of the postoperative resection cavity for brain metastasis: A frameless linear accelerator-based case series and review of the technique. Int J Radiat Oncol Biol Phys 82: 95-101, 2012.

75. Jagannathan J, Yen CP, Ray DK, Schlesinger D, Oskouian RJ, Pouratian N, Shaffrey ME, Larner J and Sheehan JP: Gamma Knife radiosurgery to the surgical cavity following resection of brain metastases. J Neurosurg 111: 431-438, 2009.

76. Foletto MC and Haas SE: Cutaneous melanoma: New advances in treatment. An Bras Dermatol 89: 301-310, 2014. 